\title{
Positioning of cassava cultivars in space management and use of biostimulant
}

\author{
Adriano Udich Bester ${ }^{1}{ }^{\complement}$, Ivan Ricardo Carvalho, ${ }^{1, *}$, José Antonio Gonzalez da Silva ${ }^{1}{ }^{\circ}$, Danieli

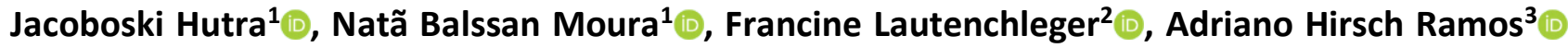 \\ and Cristiano Dietrich Ferreira ${ }^{4}(\mathbb{D}$
}

${ }^{1}$ Universidade Regional do Noroeste do Estado do Rio Grande do Sul (Unijuí), ljuí, Brazil. ${ }^{2}$ Universidade Estadual do Centro-Oeste (Unicentro), Guarapuava, PR, Brazil. ${ }^{3}$ Department of Agroindustrial Science and Technology, Federal University of Pelotas (UFPEL), Rio Grande do Sul, Brazil. ${ }^{4}$ Technological Institute in Food for Health, University of Vale do Rio dos Sinos (Unisinos), São Leopoldo, Rio Grande do Sul, Brazil. *Corresponding author, E-mail: carvalho.irc@gmail.com

\begin{abstract}
Cassava plays a fundamental role in food, economy, culture and in Brazilian society. Because it is a rustic crop, tolerant to drought and acidic soils, with high adaptive capacity and low production cost, it has become the main source of carbohydrate in much of the world. Due to this and other factors, the presumed work aims to evaluate four cassava genotypes, transplanted in two different densities with the use of a biostimulant for root growth. The present study was carried out in the experimental area of Regional University of Northwest Rio Grande do Sul, in the county of Augusto Pestana - RS, Brazil. The treatments consisted of three cassava cultivars, FEPAGRO-RS 13 Vassourinha, BRS CS01, lapar - 19 Pioneira with two planting densities, 10 and 20 buds per linear meter, with and without the use of plant biostimulator Sturdy ${ }^{\circledast}$. The evaluations were carried out throughout the crop cycle, post-harvest and processing. Where the following variables were evaluated: plants emerged at 30,60 and 90 days, plants that tuberized, starch, plant height, stem diameter, total root length, lignified part of the root, commercial root length, mean root diameter, number of leaves, branching of the stems, roots that tuberized and not tuberized, mass of tuberized roots, fresh mass of commercial tuber with peel, fresh mass of commercial tuber without peel, mass of partially dry peeled tuber. Regarding the density, the one that showed a better performance in the productive character was the density 10 buds per linear meter, which presented the highest averages of the commercial fresh mass without peel. Taking into account the cultivars, the one with the highest fresh mass production was BRS CS01 and lapar-19 Pioneira. However, FEPAGRO-RS 13 Vassourinha presented a higher percentage of starch. The application of the biostimulant of root growth showed significant effect mainly for the characteristics of productivity. The increase in the number of branches decreases the final productivity of the crop. Another point to consider, the larger the average root diameter, the greater the percentage of starch in the root. By the method of Annicchiarico it can be pointed out that in general the percentage of starch and the dry matter of the roots had a better behavior in density 10 with biostimulant and density 20 with biostimulant.
\end{abstract}

Keywords: Manihot esculenta, sustainability, human food, quality, spacing, root growth.

\section{INTRODUCTION}

Cassava plays a fundamental role in food, economy, culture and in Brazilian society. Being cultivated by the indigenous people before the arrival of the colonizers, your roots are intertwined with the emergence of our country. Because it is a rustic crop, tolerant to drought and acidic soils, with high adaptive capacity and low production cost, it has become the main source of carbohydrate in much of the world. It is widely cultivated in Tropical Africa, Asia and Latin America, being the main food of almost one billion people in more than 100 countries, providing up to a third of the daily calories, largely by developing countries (Albuquerque et al., 2012; Miranda, Spinosa, Destro, Souza-Junior, \& Nascimento, 2019; Miranda, Spinosa, Destro, Souza-Junior, \& Nascimento, 2020).

In recent years, the trend of increasing cassava productivity in Brazil has been almost nil, and often negative. The constant increase of the population, causes the number of people going hungry to grow, about 820 million people did not have enough access to food, according to the UN report (2018). Thus making the food production system more and more loaded, where the cassava crop will stand out in the fight against hunger, however with much to improve in its growing, so that it expresses its total productivity 
In 2016, Brazil had a productivity of 15 ton ha ${ }^{-1}$, in 2018 it had a reduction of $7.5 \%$, with a production of 14 ton ha ${ }^{-1}$. Having an increase in 2019, presenting a productivity of 15 ton ha ${ }^{-1}$, according to projections, in 2020 there will be a reduction of $0.93 \%$ (CONAB, 2019; CONAB, 2020). This is due to the large part of Brazilian production being made by small farmers who use a rudimentary management system with the minimum of applied technology (Miranda et al., 2019).

Studies by Embrapa Amazônia Ocidental (2016) indicate a 150\% increase in cassava productivity with the use of technologies, such as soil acidity correction, fertilization, selection of plants, adequate spacing and weed control. Studies by Embrapa Agropecuária Oeste together with Cooperativa Agrícola Sul Matogrossense, hope to obtain gains of up to $50 \%$ in productivity with the use of new cultivars developed by Embrapa. They are BRS CS01, BRS 420, for industry, and cultivars BRS 396, BRS 399 and BRS 429, for table.

Despite being a rustic crop, the management must be carried out in an appropriate way, and have climatic conditions to express its maximum potential, presenting high yields, many Brazilian regions have their own cultivars, adapted to the conditions of the region. Since the crop has a great influence of the edaphoclimatic conditions, that is, it presents a high genotype $x$ environment interaction, indicating that the same material hardly behaves in a similar way in all regions (Abreu, Bicudo, Brachtvogel, Curcelli, \& Aguiar, 2008).

Planting density is one of the pillars of cassava productivity, because when there is an increase in population density, productivity increases until it reaches an inflection point, from which it decreases. However, most of the works found in the literature relate the spacing effect only to the production of tuberous roots. Therefore, there is a lack of information about which density is the best and to clarify the effect of different spacing, which are conditioning factors of tuberous roots productivity in cassava, in its growth and development (Streck et al., 2014).

There is a constant demand for alternative tools that increase crop productivity. In this sense, an alternative is the use of plant regulators, they are compounds that have the ability to bring effects, such as accelerating the growth of plants, improving their defenses or stimulating the germinative power. Due to this and other factors, the presumed work aims to evaluate four cassava genotypes, transplanted in two different densities with the use of a biostimulant for root growth.

\section{MATERIALS AND METHODS}

The present study was carried out in the experimental area of the Regional Institute for Rural Development (IRDeR), belonging to the Department of Agrarian Studies of the Regional University of Northwest Rio Grande do Sul, in the county of Augusto Pestana - RS, located at $28^{\circ} 26^{\prime} 30^{\prime \prime} \mathrm{S}$ and $54^{\circ} 00^{\prime} 58^{\prime \prime}$ $\mathrm{W}$, altitude $280 \mathrm{~m}$. The soil in the experimental area is classified as a Typical Dystrophic Red Latosol (Oxisol) (SANTOS et al., 2019).

Analytical results for soil sampled in the experiment area, in the $0-20 \mathrm{~cm}$ and $20-40 \mathrm{~cm}$ layers. Chemical attributes how clay content (57 \%) classified class 2, pH water (5), Aluminum (0,2), Phosphorus (16,9 mg $\mathrm{dm}^{-3}$ ) and Potassium (230 mg dm $\mathrm{m}^{-3}$ ) classified in very high, Organic matter $(3,7 \%)$ classified in medium,

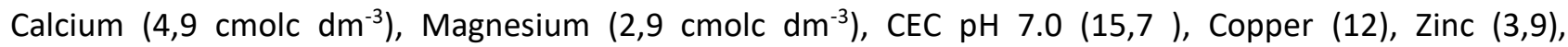
Manganese $(150)$ e Sulfur $(13,4)$ classified in high.

According to the climatic characterization of Köeppen, the climate of the region is of the Cfa type (humid subtropical), with four distinct seasons. The average annual temperature is $19.9^{\circ} \mathrm{C}$ and the average annual rainfall is $1,774 \mathrm{~mm}$.

The treatments consisted of three cassava cultivars, FEPAGRO-RS 13 Vassourinha, BRS CS01, lapar - 19 Pioneira with two planting densities, 10 and 20 buds per linear meter, with and without the use of plant biostimulator Sturdy ${ }^{\circledR}$. The plots consisted of 6 linear meters, according to the treatments, with a spacing of one meter between lines. The design used was randomized blocks in a triple factorial scheme, with 3 cultivars $\times 2$ planting densities $\times 2$ forms of plant regulator (with and without) with three repetitions.

The experimental area had the dimensions of $16 \mathrm{~m}$ long $\times 22 \mathrm{~m}$ wide, totaling an area of $352 \mathrm{~m}^{2}$. The soil preparation was performed two weeks before planting, by mowing the area, which contained a mix of radish, wheat and black oats as soil cover. After mowing, the area was subsoiled using a subsoiler and opening the planting lines. The soil was corrected, based on the interpretation of the results of the soil analysis, even though the crop tolerating acidic soils, 2 ton ha ${ }^{-1}$ of lime was applied after the soil preparation, in order to increase the levels of calcium and magnesium in the soil. (Tironi et al., 2019). 
The planting took place on September 27, 2019, according to recommendations of the agroclimatic risk zoning of cassava for the state of Rio Grande do Sul (Maluf, Matzenauer, \& Maluf, 2011). The branches were sawn in such a way that each branch had only one bud, after which it was separated into two equal parts where one was made to treat the branches with the Sturdy product from the company Satis. To prepare the mixture, $300 \mathrm{ml}$ of the product were used in 20 liters of water, after the branches were dipped for a minimum of $2 \mathrm{~min}$ in the mixture, then removed and left to dry for $10 \mathrm{~min}$. The pits were opened manually, and the stems were placed horizontally at the bottom of the pits. Fertilization was carried out based on soil analysis (Table 1), where $400 \mathrm{~kg} \mathrm{ha}^{-1}$ of the fertilizer formulated 10-20-20 were used between the planting lines, and $350 \mathrm{~kg}$ of urea in top dressing were used 45 days after planting, according to the Liming and Fertilization Manual for the States of Rio Grande do Sul and Santa Catarina (2016).

Table 1. Cassava crop variance analysis for seven variables analyzed, observing the different cultivars, densities and application of biostimulants.

\begin{tabular}{|c|c|c|c|c|c|c|}
\hline \multirow{2}{*}{ Source of variation } & \multirow{2}{*}{ DF } & \multicolumn{5}{|c|}{ Mean squares } \\
\hline & & EC $30^{1}$ & EC 60 & EC 90 & PTUBER & $\mathrm{CHO}$ \\
\hline Blocks (B) & 2 & 408.87 & 531.62 & $605.96^{*}$ & $569.12^{*}$ & 2.00 \\
\hline Cultivars (C) & 2 & $596.55^{*}$ & $598.22 *$ & $446.01^{*}$ & $426.76^{*}$ & 3.31 \\
\hline Biostimulants (B) & 1 & 23.63 & 0.69 & 1.93 & 1.56 & 10.55 \\
\hline Densities (D) & 1 & 139.37 & 434.03 & $696.37^{*}$ & $748.63^{*}$ & 18.83 \\
\hline $\mathrm{C} \times \mathrm{B}$ & 2 & 29.30 & 2.78 & 5.81 & 15.8 & 10.00 \\
\hline$C \times D$ & 2 & 67.38 & 5.01 & 18.77 & 19.12 & $40.2^{*}$ \\
\hline$B \times D$ & 1 & 311.13 & 268.6 & 233.41 & 189.06 & 0.86 \\
\hline$C \times B \times D$ & 2 & 412.64 & 348.47 & 318.54 & 306.31 & 4.73 \\
\hline Residues & 22 & 141.51 & 150.03 & 136.41 & 126.8 & 7.32 \\
\hline Total & 35 & - & - & - & - & - \\
\hline CV (\%) & - & 7.26 & 6.51 & 6.53 & 6.73 & 36.38 \\
\hline \multirow{2}{*}{ Source of variation } & & \multirow{2}{*}{ DF } & \multicolumn{4}{|c|}{ Mean squares } \\
\hline & & & \multicolumn{2}{|r|}{$\mathbf{N L}^{1}$} & \multicolumn{2}{|c|}{$\mathrm{PH}$} \\
\hline Blocks (B) & & 2 & \multicolumn{2}{|r|}{63.98} & \multicolumn{2}{|c|}{0.82} \\
\hline Cultivars (C) & & 2 & \multicolumn{2}{|r|}{$3004.72 *$} & \multicolumn{2}{|c|}{$61614.39 *$} \\
\hline Biostimulants (B) & & 1 & \multicolumn{2}{|r|}{630.7} & \multicolumn{2}{|c|}{255.45} \\
\hline Densities (D) & & 1 & \multicolumn{2}{|r|}{$4185.43^{*}$} & \multicolumn{2}{|c|}{3063.96} \\
\hline $\mathrm{C} \times \mathrm{B}$ & & 2 & \multicolumn{2}{|r|}{165.17} & \multicolumn{2}{|c|}{1329.39} \\
\hline$(C \times D$ & & 2 & \multicolumn{2}{|r|}{56.17} & \multicolumn{2}{|c|}{1601.09} \\
\hline$B \times D$ & & 1 & \multicolumn{2}{|r|}{102.93} & \multicolumn{2}{|c|}{4.61} \\
\hline$C \times B \times D$ & & 2 & \multicolumn{2}{|r|}{809.19} & \multicolumn{2}{|c|}{3443.84} \\
\hline Residues & & 22 & \multicolumn{2}{|r|}{635.1} & \multicolumn{2}{|c|}{9523.12} \\
\hline Total & & 35 & \multicolumn{2}{|r|}{-} & \multicolumn{2}{|c|}{-} \\
\hline CV (\%) & & - & \multicolumn{2}{|r|}{8.36} & \multicolumn{2}{|c|}{2.27} \\
\hline
\end{tabular}

*significant at $5 \%$ probability.

1EC 30: Plants emerged at 30 days; EC 60: Plants emerged at 60 days; EC 90: Plants emerged at 90 days; PTUBER: Tuberized plants; CHO: Starch; NL: Number of Leaves; PH: Plant Height.

The evaluations were carried out throughout the crop cycle, post-harvest and processing. Where the following variables were evaluated: plants emerged at 30, 60 and 90 days (EC 30, EC 60, EC 90), plants that tuberized (PTUBER), starch (CHO), results in percentage (\%); plant height (PH), stem diameter (DIAM), total root length (TL), lignified part of the root (LP), commercial root length (CL), mean root diameter (MD), results in centimeters $(\mathrm{cm})$; number of leaves $(\mathrm{NL})$, branching of the stems (BRA), roots that tuberized (RTUBER) and not tuberized (NTUBER), results in units (units); mass of tuberized roots (MAST), fresh mass of commercial tuber with peel (MCWP), fresh mass of commercial tuber without peel (MCNP), mass of 
The method of Annicchiarico (1992) is based on the analysis of variance where the sums of squares of the simple effects are weighted by the eco-valency method where inferences are attributed to favorable, unfavorable and general environments, these being defined by the construction of the environmental index (Silva, Carvalho, \& Magano, 2020).

The data obtained were subjected to analysis of variance, the diagnosis of normality (Shapiro \& Wilk, 1965) and homogeneity of variances (STEEL et al., 1997) were performed, the variables that showed interaction between cultivars $x$ planting densities $x$ forms of plant regulator, were broken down to the simple effects based on the tukey probability matrix at $5 \%$ probability. The variables that did not show any interaction were separated into the main effects by the tukey test at $5 \%$ probability. After Pearson's linear correlation was performed in order to show the linear trend of association between the characters (Carvalho, Lorencetti, \& Benin, 2004). The method by Annicchiarico (1992) was applied to the percentage character of starch and root dry mass and followed the methodology proposed by Cruz, Carneiro and Regazzi (2014). The information on the growth and development of the culture in the face of the evaluation days and the climatological effects were demonstrated graphically with descriptive appreciation. In order to identify the multivariate profile of the treatments, the average Euclidean algorithm was used and the distance matrix was obtained, which was used to employ the UPGMA method, and the dendrogram was constructed as well as the analysis of the Biplot main components. The software used was the R program, using the agricoline Exp.Des packages, metan ggplot2.

\section{RESULTS AND DISCUSSION}

In the analysis of variance (Table 2), significance was obtained at $5 \%$ probability for block in the analyzed variables plants emerged at 90 days (EC 90) and plants that tuberized (PTUBER), for cultivar, superiority was observed for the plant factors emerged at 30 days (EC 30), plants emerged at 60 days (EC 60), plants emerged at 90 days (EC 90), plants that tuberized (PTUBER), number of leaves (NL) and plant height (PH). For density variation factor, there were significant values for plants emerged at 90 days (EC 90), plants that tuberized (PTUBER) and number of leaves (NL). There was a significant difference for the interaction between cultivar $x$ density when starch was evaluated.

Table 3 describes the results obtained for the block variation factor, where there was a significant difference for mean root diameter, for cultivar and density and interaction between cultivar $\mathrm{x}$ biostimulant $x$ density, which was significant for roots that tuberized (RTUBER), total root length (TL), comercial root length (CL), fresh mass of commercial tuber with peel (MCWP), fresh mass of commercial tuber without peel (MCNP) and mass of partially dry peeled tuber (MPDPT), for the latter variation also obtained significance for mean root diameter (MD). The interaction between cultivar and biostimulant showed a relevant difference for fresh mass of commercial tuber with peel (MCWP), fresh mass of commercial tuber without peel (MCNP) and mass of partially dry peeled tuber (MPDPT). For biostimulant $x$ density, there was a difference in the variable total root length (TL).

When the variable tuberized roots (RTUBER) was analyzed (Table 4), comparing the cultivars within the treatments, the cultivar lapar-19 Pioneira showed higher values for density 10 with biostimulant, without biostimulant there was no significant difference. Density 20 with biostimulant also showed no difference between cultivars, and without biostimulant, cultivar FEPAGRO-RS 13 Vassourinha was inferior to the others. The cultivar FEPAGRO-RS 13 Vassourinha showed higher RTUBER without the application of biostimulant at density 10, BRS CSO1 showed no difference with and without the application of biostimulant and lapar-19 Pioneira was superior with the application of biostimulant. In density 20 there was no difference when using treatments with and without biostimulant application. When the cultivars with the application of biostimulant in different densities were evaluated, only the cultivar lapar-19 Pioneira was inferior to the others. Without biostimulant only the cultivar FEPAGRO-RS 13 Vassourinha showed lower values compared to the others.

For the variable total length (TL), the cultivars BRS CS01 and lapar-19 Pioneira were superior in density 10 with the application of biostimulant, for the same density without the use of hormone, only the cultivar BRS CS01 was superior. When analyzing cultivars at density 20 using biostimulant, only BRS CS01 showed higher values for TL, and did not differ significantly without the use of it. For density 10 with and without biostimulant, only the cultivar BRS CSO1 with use was shown to be inferior to the others, in density 20 without the application the same cultivar has shown to be inferior. When comparing the use of biostimulants in different densities, the cultivar lapar-19 Pioneira was inferior using hormone at density 20, 
without use, BRS CS01 was inferior at density 20.

Table 2. Cassava crop variance analysis for eight variables analyzed, observing the different cultivars, densities and application of biostimulants.

\begin{tabular}{cccccccccc}
\hline \multirow{2}{*}{$\begin{array}{c}\text { Source of } \\
\text { variation }\end{array}$} & DF & \multicolumn{1}{c}{$\begin{array}{c}\text { RTUB } \\
\text { ER }\end{array}$} & TL & MD & CL & MAST & MCWP & MCNP & MPDPT \\
\hline Blocks (B) & 2 & 0.05 & 49.73 & $0.60^{*}$ & 33.87 & 479281.27 & 407486.17 & 295743.11 & 33926.78 \\
Cultivars (C) & 2 & $31.32^{*}$ & $1606.19^{*}$ & 0.70 & $743.68^{*}$ & 5146346.32 & $2984750.96^{*}$ & $2491738.64^{*}$ & $348822.48^{*}$ \\
Biostimulants (B) & 1 & 1.42 & 30.75 & 0.29 & 26.33 & 1.60 & 67977.80 & 66097.02 & 6471.72 \\
Densities (D) & 1 & $21.36^{*}$ & $188.6^{*}$ & 0.81 & $122.23^{*}$ & 4951783.47 & $4421133.89^{*}$ & $2479476.46^{*}$ & $542689.81^{*}$ \\
Cx B & 2 & 3.54 & 2.11 & 0.45 & 22.86 & 1133645.40 & $909410.97^{*}$ & $1116121.86^{*}$ & $130876.26^{*}$ \\
Cx D & 2 & 2.64 & 76.23 & 0.10 & 52.48 & 691685.04 & 612523.49 & 145379.09 & 22385.39 \\
B x D & 1 & 0.36 & $175.36^{*}$ & 0.01 & 42.22 & 523.60 & 24220.80 & 155056.64 & 4970.60 \\
Cx B x D & 2 & $19.90^{*}$ & $279.24^{*}$ & $2.61 *$ & $119.78^{*}$ & 1283916.04 & $1120687.80^{*}$ & $1073858.36^{*}$ & $94541.66^{*}$ \\
Residues & 22 & 2.96 & 38.65 & 0.27 & 32.18 & 307244.68 & 291510.06 & 180461.04 & 32464.69 \\
\hline Total & 35 & - & - & - & - & - & - & - & - \\
\hline CV (\%) & - & 28.10 & 10.44 & 32.20 & 10.06 & 0.19 & 0.19 & 0.30 & 0.60 \\
\hline
\end{tabular}

*Significant at $5 \%$ probability.

${ }^{1}$ RTUBER: Tuberized roots; TL: Root total length; MD: Mean root diameter; CL: Root commercial length; MAST: Total mass of tuberized roots; MCWP: Fresh mass of commercial tuber with peel; MCNP: Fresh mass of commercial tuber without peel; MPDPT:

Mass of partially dry peeled tuber.

The commercial length $(\mathrm{CL})$ variable showed higher values with the application of hormone at density 10 for lapar-19 Pioneira and BRS CS01, and this was higher without the application of hormone. All cultivars were superior for this variable, except BRS CS01 for density 10 with biostimulant and density 20 without biostimulant. When comparing densities and biostimulants, only the cultivar BRS CSO1 was lower in density 20 without hormone application.

For the variable mean root diameter (MD), the cultivars did not differ significantly in density 10 with the application of biostimulant, without application, the cultivar lapar-19 Pioneira showed lower values, whereas in density 20, with application, the cultivar BRS CS01 and lapar-19 Pioneira were superior, the cultivar FEPAGRO-RS 13 Vassourinha was superior when hormone was not applied. When comparing the densities with and without application, only the cultivars FEPAGRO-RS 13 Vassourinha and BRS CS01, at density 20 with and without biostimulant, respectively, obtained lower values. In a study by Pina Filho (2018), there was an increase in the mean diameter of the roots in plants grown in double rows, which have a smaller spacing between plants. The author also found that the increase in diameter is a response of the root morphology to the ability to adapt to adverse environmental conditions.

When tuberized root mass (MAST) was evaluated, all cultivars, except FEPAGRO-RS 13 Vassourinha, showed higher values with application and density 10, without application only the cultivar BRS CSO1 was superior. At density 20, with application, the cultivar BRS CSO1 stood out from the others, without biostimulant, they did not differ from each other. For the comparison between the use and not of biostimulant, only the cultivar lapar-19 Pioneira showed a lower value in density 10 without application. The cultivars BRS CS01 and lapar-19 Pioneira showed lower values for handling without application of biostimulant at density 20 buds per linear meter. 
Table 3. Test of comparison of means for seven variables analyzed in the cassava crop, observing the different cultivars, densities and application of biostimulants.

\begin{tabular}{|c|c|c|c|c|}
\hline & \multicolumn{4}{|c|}{ Densities } \\
\hline & & & & \\
\hline & & Bio & nts & \\
\hline \multirow{2}{*}{ Cultivars } & With & Without & With & Without \\
\hline & \multicolumn{4}{|c|}{ RTUBER $^{1}$} \\
\hline FEPAGRO-RS 13 Vassourinha & $3.93 \mathrm{bB} \alpha^{*}$ & $5.20 \mathrm{aA} \alpha$ & $4.40 \mathrm{aA} \alpha$ & $3.47 \mathrm{bA} \beta$ \\
\hline BRS CS01 & $4.40 \mathrm{bA} \alpha$ & $4.27 \mathrm{aA} \alpha$ & $3.93 \mathrm{aA} \alpha$ & $4.13 \mathrm{abA} \alpha$ \\
\hline \multirow[t]{2}{*}{ lapar-19 Pioneira } & $7.00 \mathrm{aA} \alpha$ & $5.07 \mathrm{aB} \alpha$ & $4.67 \mathrm{aA} \beta$ & $5.13 \mathrm{aA} \alpha$ \\
\hline & \multicolumn{4}{|c|}{ TL } \\
\hline FEPAGRO-RS 13 Vassourinha & $22.11 \mathrm{bA} \alpha$ & $21.43 \mathrm{cA} \alpha$ & $22.34 \mathrm{bA} \alpha$ & $22.16 \mathrm{aA} \alpha$ \\
\hline BRS CS01 & $30.71 \mathrm{aB} \alpha$ & $36.77 \mathrm{aA} \alpha$ & $34.88 \mathrm{aA} \alpha$ & $27.05 \mathrm{aB} \beta$ \\
\hline \multirow[t]{2}{*}{ lapar-19 Pioneira } & $29.81 \mathrm{aA} \alpha$ & $27.87 \mathrm{bA} \alpha$ & $25.19 \mathrm{bA} \beta$ & 24.79 aA $\alpha$ \\
\hline & \multicolumn{4}{|c|}{$\mathrm{CL}$} \\
\hline FEPAGRO-RS 13 Vassourinha & $20.84 \mathrm{bA} \alpha$ & $20.67 \mathrm{bA} \alpha$ & $21.22 \mathrm{bA} \alpha$ & $21.31 \mathrm{aA} \alpha$ \\
\hline BRS CS01 & $27.32 \mathrm{aB} \alpha$ & $31.44 \mathrm{aA} \alpha$ & $28.78 \mathrm{aA} \alpha$ & $24.55 \mathrm{aB} \beta$ \\
\hline \multirow[t]{2}{*}{ lapar-19 Pioneira } & $27.04 \mathrm{aA} \alpha$ & $23.71 \mathrm{bA} \alpha$ & $23.16 \mathrm{bA} \alpha$ & $22.11 \mathrm{aA} \alpha$ \\
\hline & \multicolumn{4}{|c|}{ MD } \\
\hline FEPAGRO-RS 13 Vassourinha & $3.66 \mathrm{aA} \alpha$ & $3.55 \mathrm{abA} \alpha$ & $3.14 \mathrm{bB} \beta$ & $3.79 \mathrm{aA} \alpha$ \\
\hline BRS CS01 & $3.39 \mathrm{aB} \alpha$ & $3.87 \mathrm{aA} \alpha$ & $3.62 \mathrm{aA} \alpha$ & $3.22 \mathrm{bB} \beta$ \\
\hline \multirow[t]{2}{*}{ lapar-19 Pioneira } & $3.44 \mathrm{aA} \alpha$ & $3.28 \mathrm{bA} \alpha$ & 3. $29 \mathrm{abA} \alpha$ & $3.33 \mathrm{bA} \alpha$ \\
\hline & \multicolumn{4}{|c|}{ MAST } \\
\hline FEPAGRO-RS 13 Vassourinha & $770.1 \mathrm{bA} \alpha$ & $1008.9 \mathrm{bA} \alpha$ & $728.0 \mathrm{bA} \alpha$ & $862.2 \mathrm{aA} \alpha$ \\
\hline BRS CS01 & 1413.9 aA $\alpha$ & $1806.2 \mathrm{aA} \alpha$ & $1296.4 \mathrm{aA} \alpha$ & 1169.6 aA $\beta$ \\
\hline \multirow[t]{2}{*}{ lapar-19 Pioneira } & $1795.2 \mathrm{aA} \alpha$ & $1160.4 \mathrm{bB} \alpha$ & $956.5 \mathrm{bA} \alpha$ & 958.8 aA $\beta$ \\
\hline & \multicolumn{4}{|c|}{ MCWP } \\
\hline FEPAGRO-RS 13 Vassourinha & $805.1 \mathrm{bA} \alpha$ & $967.7 \mathrm{bA} \alpha$ & 753.9 aA $\alpha$ & $836.5 \mathrm{aA} \alpha$ \\
\hline BRS CSO1 & $1315.9 \mathrm{aA} \alpha$ & $1612.0 \mathrm{aA} \alpha$ & $1165.9 \mathrm{aA} \alpha$ & 1036.0 aA $\beta$ \\
\hline \multirow[t]{2}{*}{ lapar-19 Pioneira } & $1681.5 \mathrm{aA} \alpha$ & $1036.7 \mathrm{bB} \alpha$ & $872.8 \mathrm{aA} \beta$ & $873.1 \mathrm{aA} \alpha$ \\
\hline & \multicolumn{4}{|c|}{ MCNP } \\
\hline FEPAGRO-RS 13 Vassourinha & $805.1 \mathrm{bA} \alpha$ & $967.7 \mathrm{bA} \alpha$ & $753.9 \mathrm{aA} \alpha$ & 836.5 aA $\alpha$ \\
\hline BRS CS01 & $1315.9 \mathrm{aA} \alpha$ & $1612.0 \mathrm{aA} \alpha$ & $1165.9 \mathrm{aA} \alpha$ & $1036.0 \mathrm{aA} \beta$ \\
\hline lapar-19 Pioneira & 1681.5aA $\alpha$ & 1036.7 bBa & 872.8 aA $\beta$ & $873.1 \mathrm{aA} \alpha$ \\
\hline
\end{tabular}

* Means followed by the same lower case letter in the column compare cultivars, upper case compares hormones in the same density and Greek letter between densities and biostimulants do not differ by Tukey's test at $5 \%$ probability.

${ }^{1}$ RTUBER: Tuberized roots; TL: Root total length; CL: Root commercial length; MD: Mean root diameter; MAST: Mass of tuberized roots; MCWP: Fresh mass of commercial tuber with peel; MCNP: Fresh mass of commercial tuber without peel. 
Table 4. Test of comparison of means for eight variables analyzed in the cassava crop, observing the different cultivars, densities and application of biostimulants.

\begin{tabular}{|c|c|c|c|}
\hline \multicolumn{4}{|c|}{ MPDPT $^{1}$} \\
\hline \multirow[b]{2}{*}{ Biostimulants } & \multicolumn{3}{|c|}{ Cultivars } \\
\hline & $\begin{array}{c}\text { FEPAGRO-RS } 13 \\
\text { Vassourinha }\end{array}$ & BRS CS01 & lapar-19 Pioneira \\
\hline With & $236.7 \mathrm{Ab}^{*}$ & 401.0 Aa & $385.4 \mathrm{Aa}$ \\
\hline \multirow[t]{3}{*}{ Without } & $290.8 \mathrm{Ab}$ & $429.8 \mathrm{Aa}$ & $266.6 \mathrm{Bb}$ \\
\hline & \multicolumn{2}{|c|}{$\mathrm{CHO}$} & \\
\hline & \multicolumn{3}{|c|}{ Cultivars } \\
\hline Densities & $\begin{array}{c}\text { FEPAGRO-RS } 13 \\
\text { Vassourinha }\end{array}$ & BRS CS01 & lapar-19 Pioneira \\
\hline 10 & $8.78 \mathrm{a}$ & $7.40 \mathrm{~b}$ & $5.73 c$ \\
\hline \multirow[t]{2}{*}{20} & $8.92 \mathrm{a}$ & $8.54 \mathrm{a}$ & $5.10 \mathrm{a}$ \\
\hline & \multicolumn{3}{|c|}{ Cultivars } \\
\hline Variables & $\begin{array}{c}\text { FEPAGRO-RS } 13 \\
\text { Vassourinha }\end{array}$ & BRS CS01 & lapar-19 Pioneira \\
\hline EC 30 & $28.61 \mathrm{a}$ & $15.76 \mathrm{~b}$ & $27.22 \mathrm{ab}$ \\
\hline EC 60 & $31.94 \mathrm{a}$ & $18.61 \mathrm{~b}$ & $29.30 \mathrm{ab}$ \\
\hline $\mathrm{NL}$ & $123.66 \mathrm{~b}$ & $136.58 \mathrm{~b}$ & $151.81 \mathrm{a}$ \\
\hline \multirow{3}{*}{ Densities } & \multicolumn{3}{|c|}{ Cultivars } \\
\hline & $\begin{array}{c}\text { FEPAGRO-RS } 13 \\
\text { Vassourinha }\end{array}$ & BRS CS01 & lapar-19 Pioneira \\
\hline & EC 90 & PTUBER & NL \\
\hline 10 & $30.92 \mathrm{a}$ & $30.27 \mathrm{a}$ & $37.61 \mathrm{a}$ \\
\hline 20 & $22.12 \mathrm{~b}$ & $21.15 \mathrm{~b}$ & $34.20 \mathrm{~b}$ \\
\hline
\end{tabular}

*Means followed by the same capital letter in the column and lower case in the line do not differ by Tukey's test at 5\% proba bility. ${ }^{1}$ MPDPT: Mass of partially dry peeled tuber; CHO: Starch; EC 30: Plants emerged at 30 days; EC 60: Plants emerged at 60 days; NL: Number of leaves; EC 90: Plants emerged at 90 days; PTUBER: Tuberized plants;

Fresh mass of commercial tuber with peel (MCWP), showed higher values for cultivars BRS CSO1 and lapar-19 Pioneira in density 10 with application, without application only the cultivar BRS CSO1 showed higher values, for density 20 the cultivars did not differ significantly with and without biostimulant. When the use of biostimulant was evaluated, only at density 10 without application, the cultivar lapar-19 Pioneira presented lower values. With application of biostimulant and without application at density 20, the cultivars lapar-19 Pioneira and BRS CS01 showed lower values, respectively.

For the analyzed variable, fresh mass of the commercial tuber without peel (MCNP), at density 10 with application, the cultivars lapar-19 Pioneira and BRS CS01 were superior, without application, only the latter showed a high result, at density 20 the cultivars did not differed significantly with and without application. When evaluating the use of biostimulants, the cultivar lapar-19 Pioneira showed lower values in density 10 without the use of hormones, whereas for density 20 there was no significant difference between treatments. Evaluating cultivars with and without application in densities, only in density 20 with application for cultivar lapar-19 Pioneira and without application for cultivar BRS CSO1.

As shown in Figure 1, there was a linear increase in the number of leaves and plant height during the crop cycle until harvest, however, it cannot be said that it reached its peak, since the crop was in full development at the time of harvest. Taking into account the region where the work was carried out, with low temperatures making it impossible for the crop to perpetuate, the maximum point, both in number of leaves (NL) and plant height (PH) occurs in the month of April. When there are lower night temperatures, with a high leaf area index, shading and subsequent senescence of the leaves occur, causing the plants to go into dormancy, opposite to what was observed in this experiment. 

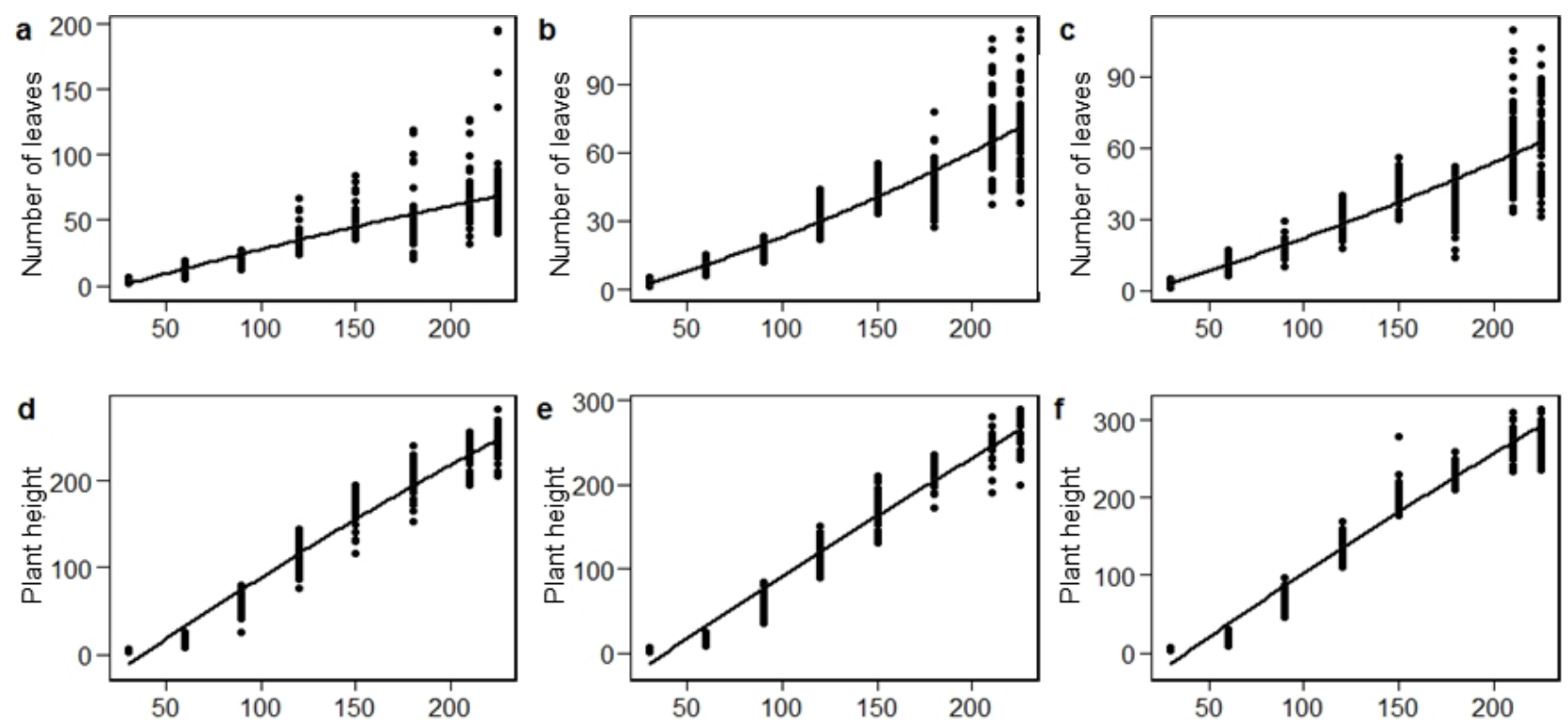

Figure 1. Growth of cultivars according to the days after planting, number of leaves and plant height for cultivars FEPAGRO-RS 13 Vassourinha (a, d), BRS CS01 (b, e), lapar- 19 Pioneira (c, f).

This factor may be linked to high planting density, leading plants to compete for radiation, with greater vegetative growth (Tironi et al, 2019). Another reason may be related to precipitation, below the usual (Figure 2), where the delay in the development of the crop was observed. When water deficit occurs, there is a reduction in the growth of the shoot, helping to conserve water, after this condition, cassava tends to increase the formation of new leaves with higher photosynthetic rates (Gabriel et al., 2014).

The cultivar FEPAGRO-RS 13 Vassourinha showed greater amplitude among the cultivars, where plants with 200 leaves were observed (Figure 3), the other cultivars, BRS CS01 and lapar-19 Pioneira did not present more than 100 leaves per plant, however, they showed higher plant height (PH), reaching three meters, it can be inferred that the distance between nodes of the two cultivars is greater than the cultivar FEPAGRO-RS 13 Vassourinha, which had a population of plants up to 2 meters high.

When the variable stem branching (BRA) was evaluated, the cultivar FEPAGRO-RS 13 Vassourinha (Figure 4), showed little branching, a characteristic of the cultivar that tends not to branch in the reproductive phase in the climatic conditions of the south of the country. Unlike the others that when entering the reproductive period, at 150 days after planting started to branch. In relation to this behavior, Cury (2008) mentions that there are few studies on the branching control, being able to observe in some clones the beginning of the branching in advance and occurring throughout the cycle, while others did not have branching. For the variable stem diameter (DIAM), constant values can be observed from the 200-day cycle for the cultivar FEPAGRO-RS 13 Vassourinha, lapar-19 Pioneira presented higher values, with diameters of three centimeters. The cultivar BRS CSO1 showed vegetative development, reaching a larger diameter.

To reduce the risks related to climatic phenomena, the crop was implanted within the period indicated in the ZARC, carried out at the end of September and harvested in June, with a total precipitation in the period of $1184 \mathrm{~mm}$ (Figure 2). In the 2019/20 season there were large losses due to climatic effects, with an uneven distribution of precipitation throughout the cycle, with two periods with a high concentration of rain, between the months of October and November in the vegetative phase of the crop, and during the reproductive phase, from May to June. Cassava begins to manifest its productive potential with an annual water regime greater than $600 \mathrm{~mm}$ (Gabriel et al., 2014), however, to achieve high productivity it is necessary to have 1000 to $2000 \mathrm{~mm}$ year ${ }^{-1}$ precipitations (Maluf et al., 2011). With the occurrence of lower rainfall volumes in the emergence phase, the final crop stand was compromised, low rainfall also occurred at the end of the vegetative phase and almost in the total reproductive phase, compromising the starch accumulation in the roots, decreasing the final productivity of the crop. The critical period of the crop for the purpose of water deficit occurs between the first and the fifth month after planting, comprising the beginning of tuberization. When water stress of up to 60 days occurs during this period, there may be a $32 \%$ to $60 \%$ reduction in crop productivity (Souza, Farias, Mattos, \& Fukuda, 2006).

Temperature is an important condition when it comes to the final yield of cassava, temperatures below $15{ }^{\circ} \mathrm{C}$ slow down the growth of the plant, with the ideal temperature range being between 25 and 29 o $\mathrm{C}$ (Cury, 2008). It does not tolerate temperatures above 42 o $C$, sprouting is favored with temperatures 


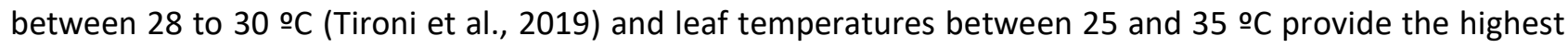
photosynthetic rates (Gabriel et al., 2014).
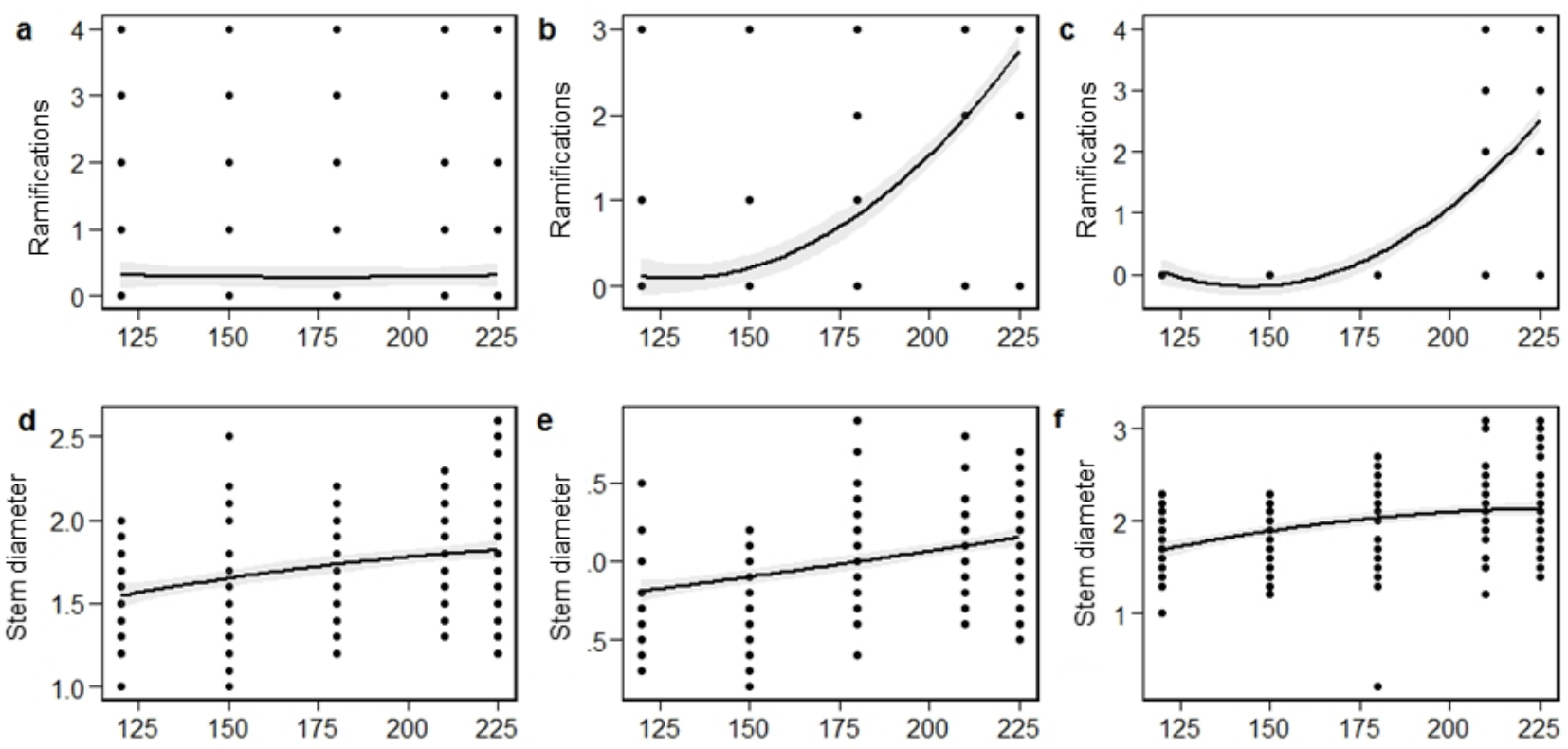

Figure 2. Growth of cultivars as a function of days after planting (DAP), ramifications and stem diameter per cultivar FEPAGRO-RS 13 Vassourinha (a, d), BRS CS01 (b, e), lapar-19 Pioneira (c, f).
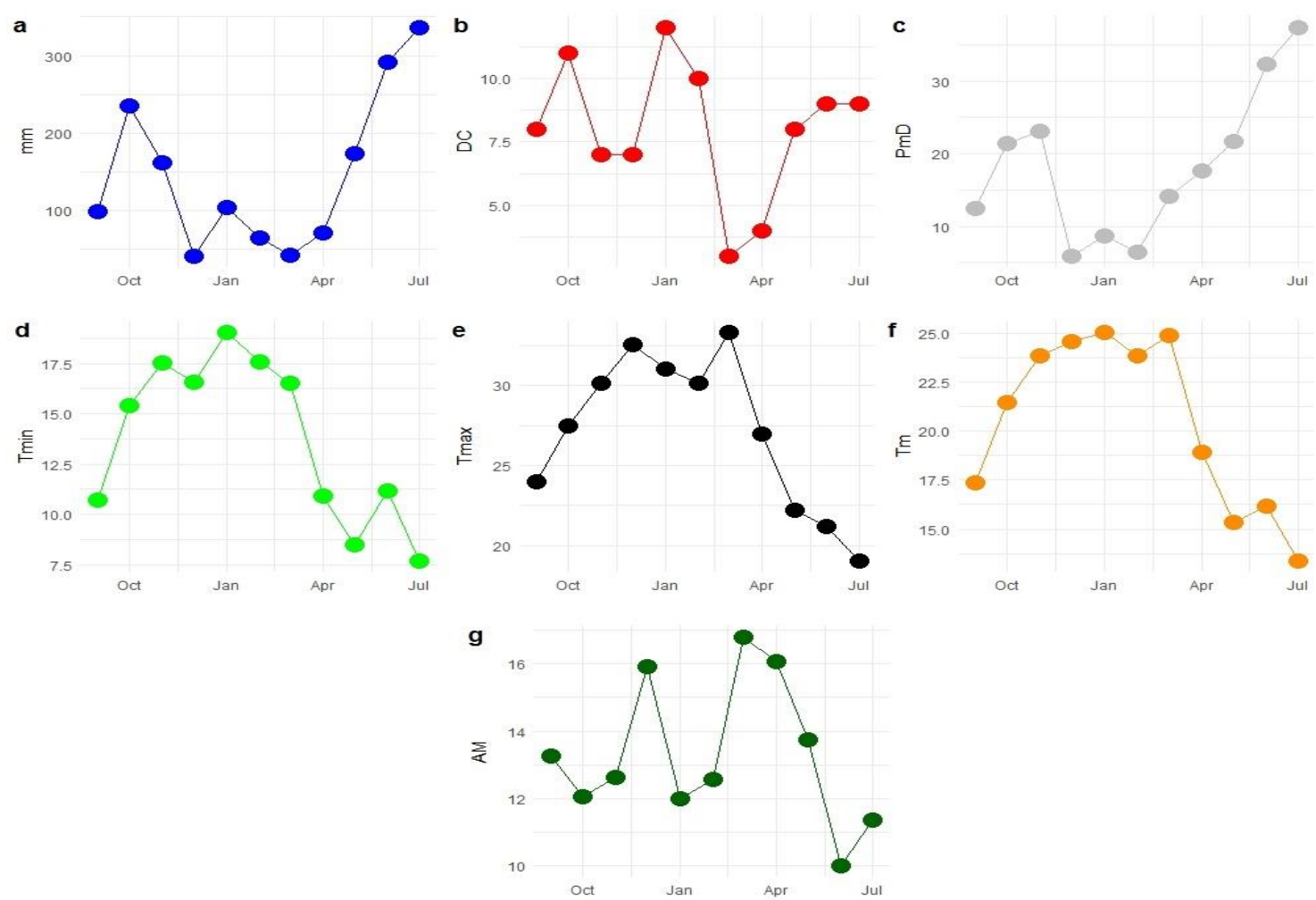

Figure 3. Graphs of climatic conditions during the development of cassava crop, rainfall (a), rainy days (b), average daily rainfall $(c)$ minimum temperature (d), maximum temperature $(e)$, average temperature (f), thermal amplitude (g).

Taking into account the data in Figure 2, it can be seen that the maximum temperature reached in the cycle was $39{ }^{\circ} \mathrm{C}$ and the minimum was $7.5^{\circ} \mathrm{C}$ in July. During the emergence stage, temperatures remained in the range of 17 to $30{ }^{\circ} \mathrm{C}$, which did not affect sprouting. In the vegetative and reproductive stages, the growth and development of the crop was not affected by the temperature, as it did not reach critical values. The average monthly temperatures were concentrated in the range of 27 to $32{ }^{\circ} \mathrm{C}$, in great part of the cycle they were in the optimal range for the development, besides the thermal conditions for the 
maximum photosynthetic rate.

\begin{tabular}{|c|c|c|c|c|c|c|c|c|c|c|c|c|c|c|}
\hline EC30 & EC60 & PTUBER & $\mathrm{NL}$ & $\mathrm{PH}$ & RAM & DIAM & TL & $\mathrm{LP}$ & $\mathrm{CL}$ & $\mathrm{MD}$ & MAST & MCWP & MPDPT & $\mathrm{CHO}$ \\
\hline H & $0.91^{\prime \prime \prime}$ & $0.85^{m}$ & $\Delta 006$ & .0 .2 & -0.25 & 0.092 & $.0 .28^{\circ}$ & -0.15 & -0.27 & 0.2 & 0018 & 0.054 & 00006 & oaves \\
\hline & & $0.98^{\prime \prime \prime}$ & 0.11 & -0.22 & -0.3 & 004 & .0 .24 & -0.19 & -0.21 & 0.21 & 0.12 & 0.15 & 0.1 & 0.14 \\
\hline & & & 0.15 & .0 .24 & $-0.33^{\circ}$ & ooven & -0.23 & -0.15 & -0.21 & 0.23 & 0.098 & 0.13 & 0.003 & 0.18 \\
\hline & & & & 0.52 & 0.3 & 0.12 & 0.16 & -0023 & 0.18 & 0.17 & 0.18 & 0.28 & $0.28^{\circ}$ & 0.1 \\
\hline & & & & & $0.73^{\prime \prime}$ & $0.38^{\circ}$ & $0.31^{\circ}$ & 0.18 & $0.29^{\circ}$ & 0.14 & $0.46^{\prime \prime}$ & $0.46^{\prime \prime}$ & $0.38^{\circ}$ & 0.17 \\
\hline & & & & & & $0.48^{\prime \prime}$ & $0.42^{\circ}$ & $0.29^{\circ}$ & $0.39^{\circ}$ & -0.21 & $0.37^{\circ}$ & $0.32^{\circ}$ & 0.27 & -0.28 \\
\hline & & & & & & & 002 & 0.15 & oass & $-0.28^{\circ}$ & 0.1 & 0045 & -00000 & -0.27 \\
\hline & & & & & & & & $0.48^{\circ}$ & 0.97 & $0.39^{\circ}$ & $0.71^{m+}$ & $0.67^{\mathrm{m}}$ & $0.66^{\prime \prime \prime}$ & 0.2 \\
\hline & & & & & & & & & 0.24 & 0.084 & 0.19 & 0.11 & 0.14 & $\Delta 0001$ \\
\hline & & & & & & & & & & $0.46^{\circ}$ & $0.73^{m-m}$ & $0.71^{m}$ & $0.69^{m+1}$ & 0.22 \\
\hline & & & & & & & & & & & $0.44^{\prime \prime}$ & $0.49^{\prime \prime}$ & $0.52^{\prime \prime}$ & $0.35^{\circ}$ \\
\hline & & & & & & & & & & & & 0.97 & 0.91 & 0.17 \\
\hline & & & & & & & & & & & & & 0.96 & 0.19 \\
\hline & & & & & & & & & & & & & & 0.14 \\
\hline & & & & & & & & & & & & & & \\
\hline
\end{tabular}

Figure 4. Estimates of Pearson's linear correlation for 15 characters of agronomic interest measured in three cassava cultivars.

${ }^{*}$ significant at $5 \%$ by the $\mathrm{t}$ test; ${ }^{* *}$ significant at $1 \%$ by t test; ${ }^{* * *}$ significant at $0.1 \%$ by $\mathrm{t}$ test.

EC 30: Plants emerged at 30 days; EC 60: Plants emerged at 60 days; PTUBER: Tuberized plants; NL: Number of leaves; PH: Plant height; BRA: Stem branching; DIAM: Stem diameter; TL: Stem total length; LP: Lignified part of the stem; CL: Root commercial length; MD: Mean root diameter; MAST: Mass of tuberized roots; MCWP: Fresh mass of commercial tuber with peel; MPDPT: Mass of partially dry peeled tuber; CHO: Starch.

Pearson's correlation coefficient shows linear correlations between the characteristics of the shoot and root parts, for Manihot esculenta. The variable plants emerged at 30 days (EC 30) showed a positive correlation with plants emerged at 60 days (EC 60) and plants that tuberized (PTUBER), indicating that the emerged plants formed the final stand of tuberized plants. Results obtained by Sangoi and Kruse (1993) pointed out that the tuberization period of the evaluated cultivars started between 60 and 90 days after planting, forming the final plant stand. The variable number of leaves (NL), demonstrated a positive correlation with plant height (PH), for the plants showing to be higher, consequently it will increase the number of leaves, favoring the interception of solar radiation increasing the production of photoassimilates (Tironi et al., 2019).

The variable stem branching (BRA) showed a positive correlation with plant height (PH), stem diameter (DIAM), total root length (TL), commercial root length (CL), tuberized root mass (MAST) and negative for roots that tuberized (RTUBER). The greater the number of branches, the smaller the tuberized roots, consequently the lower the starch concentration. Total root length (TL) demonstrated association with lignified part of the root (LP). When removing the lignified part of the total root length, we have commercial root length $(\mathrm{CL})$, which will be directly correlated to the mean root diameter (MD). These variables indicate the results of productivity, which is linked to the mass of tuberized roots (MAST), fresh mass of commercial tuber with peel (MCWP) and mass of partially dry peeled tuber (MPDPT). Where the yield per unit area is not related to the number of roots, but to its size, the root mass is linearly related to its diameter and length (Takahashi \& Guerini, 1998). The starch variable (CHO) showed a positive and significant correlation with mean root diameter (MD), so the larger the mean root diameter, the higher the starch concentration 
will be.

The dendrogram was carried out in order to gather in groups by sample data criteria, where it has homogeneity within the group and heterogeneity between groups. The genetic distance analysis generated the "cluster", showing the separation of the accessions in two main groups (Figure 5). In the first group, a division of two materials with similar genetic characteristics was obtained, the cultivar FEPAGRO-RS 13 Vassourinha and BRS CSO1. In the second group, the cultivar lapar-19 Pioneira with genetic characteristics dissimilar from the first group.

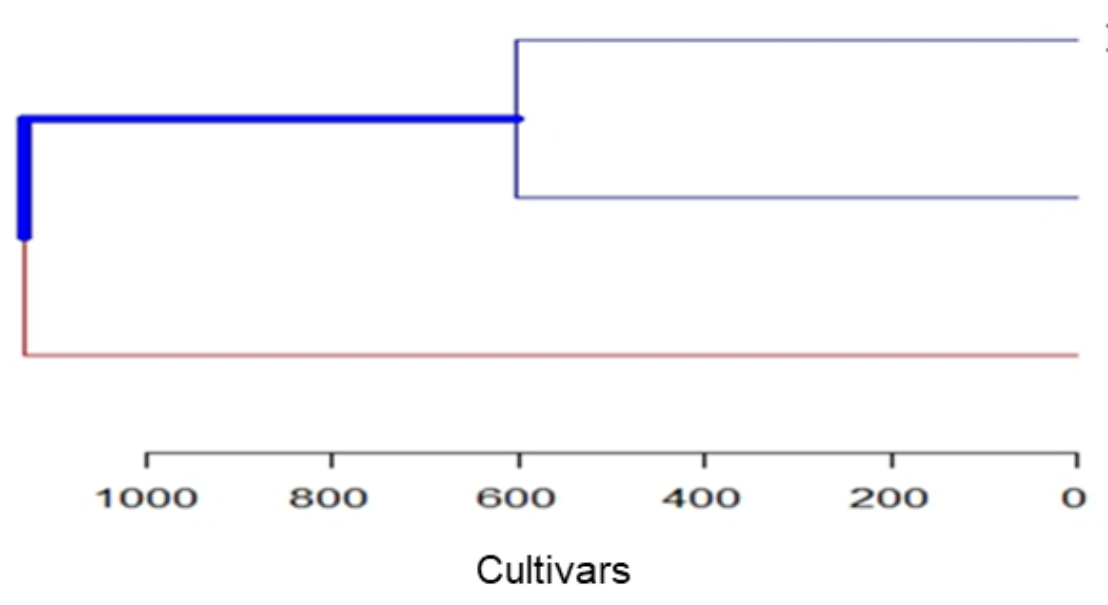

\section{BRS CS01}

FEPAGRO-RS 13 Vassourinha

Iapar- 19 Pioneira

Figure 5. Dendrogram illustrating the dissimilarity pattern based on eighteen variables for three cassava cultivars (FEPAGRO-RS 13 Vassourinha, BRS CS01, lapar-19 Pioneira).

EC 30: Plants emerged at 30 days; EC 60: Plants emerged at 60 days; EC 90: Plants emerged at 90 days; PTUBER: Tuberized plants; NL: Number of leaves; PH: Plant height; BRA: Stem branching; DIAM: Stem diameter; RTUBER: Tuberized root; NTUBER: Root not tuberized; TL: Root total length; MD: Mean root diameter; MAST: Tuberized root mass; MCWP: Fresh mass of commercial tuber with peel; MCNP: Fresh mass of commercial tuber without peel; MPDPT: Mass of partially dry peeled tuber; $\mathrm{CHO}$ : Starch.

In the biplot graph (Figure 6), the 18 main components and the three cultivars were observed, forming four distinct groups. In this modeling, Dim1 and Dim2 represent $72.5 \%$ and $27.5 \%$, respectively of the total data variance. This percentage of variance was relatively high, due to the high sample size. It can be seen in quadrant two, the variables plants emerged at 30 days (EC 30), plants emerged at 60 days (EC 60), plants emerged at 90 days (EC 90) plants that tuberized (PTUBER), not showing specific relationship with any cultivar. In quadrant three, the significant variables were mean root diameter (MD) and starch (CHO). In addition to these variables being interconnected with the cultivar FEPAGRO-RS 13 Vassourinha, it is concluded that this cultivar has a greater average root diameter and a higher percentage of starch.

The variables from the first quadrant were relevant for roots that tuberized (RTUBER), mass of partially dry peeled tuber (MPDPT), fresh mass of commercial tuber with peel (MCWP), mass of tuberized roots (MAST), fresh mass of tuber commercial without peel (MCNP), roots that did not tuberized (NTUBER) and stem branching (BRA), showing interaction with the cultivar lapar-19 Pioneira. It is noticed that, it is linked with the main components of productivity, number of tuberized roots and root mass, both with or without peel, fresh or partially dry. In the fourth quadrant, the variables that showed significance were total length $(T L)$, lignified part of the root (LP), commercial length of the root (CL), stem diameter (DIAM) and number of leaves (NL), which interacted with the cultivar BRS CSO1.

The AMMI analysis shows the effects of the genotype, environment and the interaction between them (G $x E$ ) together. The higher the percentage of the sum of the two PC axes of the AMMI analysis, explaining the total variation of the character, the higher the standard percentage with the lowest errors attributed to the analysis (Szareski, 2017 apud Oliveira et al., 2003). It can be seen that for the dry mass of the roots and for starch, the significant effects represented $100 \%$ of the sum of squares of the (G $\times E)$ interaction. 


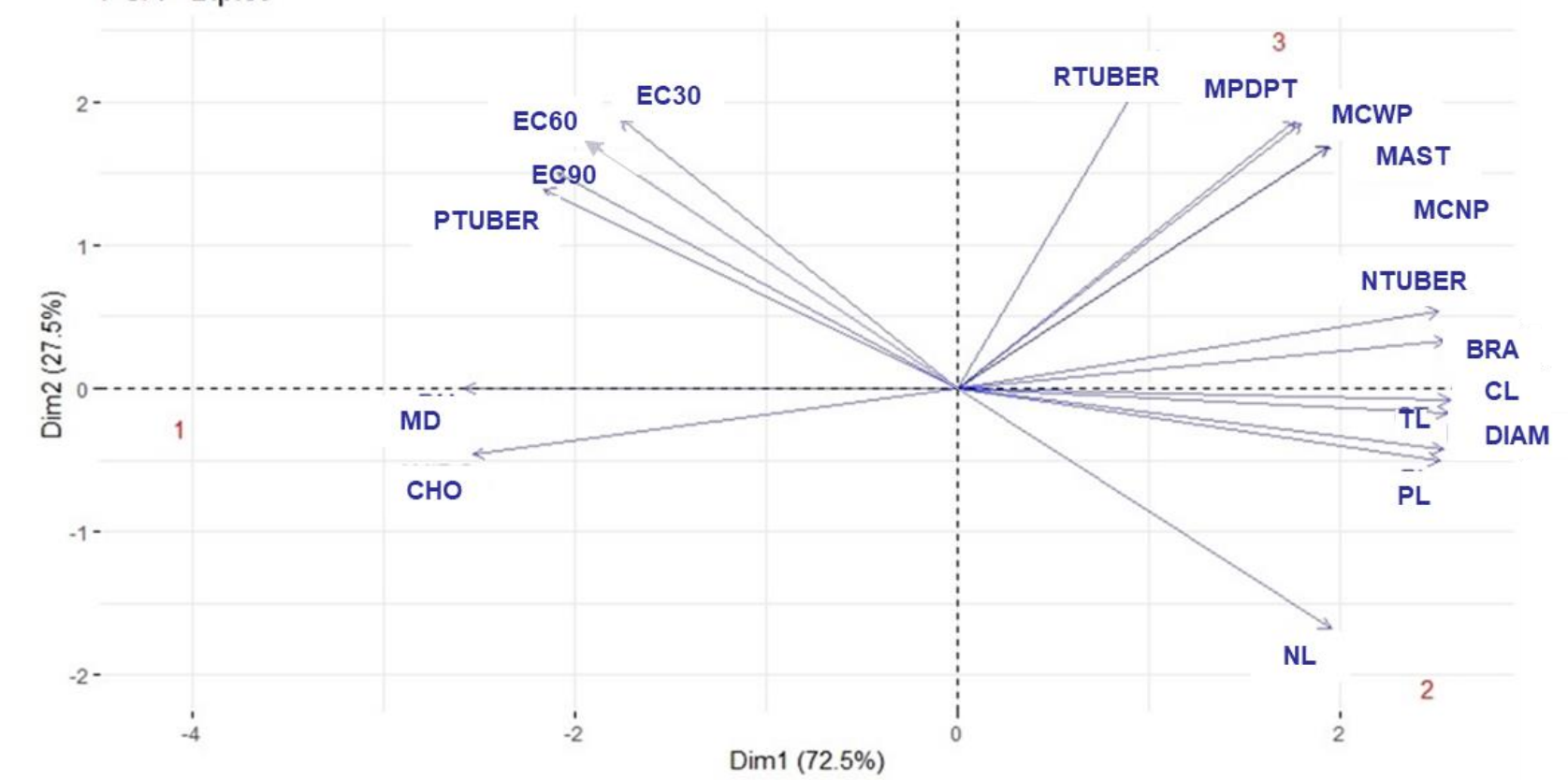

Figure 6. PCA - Biplot graph corresponding to the matrix classification of three cultivars for 18 variables.

EC 30: Plants emerged at 30 days; EC 60: Plants emerged at 60 days; EC 90: Plants emerged at 90 days; PTUBER: Tuberized plants; CHO: Starch; DIAM: Stem diameter; TL: Root total length; PL: Lignified part of the root; CL: Root commercial length; MD: Mean root diameter; NL: Number of leaves; BRA: Stem branching; RTUBER: Tuberized root; NTUBER: Root not tuberized; MAST: Tuberized root mass; MCWP: Fresh mass of commercial tuber with peel; MCNP: Fresh mass of commercial tuber without peel; MMCPS: Mass of partially dry peeled tuber.

Since a genotype is considered adapted to a given environment when it is located in the same quadrant as the environment. Thus it can be inferred that only environment three and two had interaction with cultivars BRS CS01 and FEPAGRO-RS 13 Vassourinha respectively for dry root mass (RDM) (Figure 7a). Thus, the cultivar BRS CS01, showed significant interaction with density 10 plants per linear meter without biostimulant and cultivar FEPAGRO-RS 13 Broom with density 20 plants per linear meter with biostimulant. Taking into account environment one, it showed significance, however there was not interaction between genotypes, whereas in environment four it did not show significance.

Regarding the starch content in the cassava root, it can be seen that it had a different behavior than the root dry mass (RDM) (Figure 7b). The environments that showed interaction were four and one, with the cultivars FEPAGRO-RS 13 Vassourinha and lapar-19 Pioneira respectively. That is, the cultivar lapar-19 Pioneira had interaction with the density of 10 buds per linear meter with biostimulant, and the cultivar FEPAGRO-RS 13 Vassourinha with the density of 20 buds per linear meter without biostimulant for the percentage of starch. Environment three did not interact with any cultivar, and environment two did not have a significant effect.

Regarding the phenotypic stability analysis, the Annicchiarico method (Table 5) was used, with the purpose of identifying between the three cassava genotypes and the four growing environments, which of these demonstrated effects for the percentage of starch and root dry mass, and the possibility of expressing which growing environments are favorable or unfavorable for this character. The density 10 and 20 with biostimulant was favorable to the characters root dry mass (RDM) and starch (CHO), in contrast, the same densities without biostimulant were characterized as unfavorable. Favorable environments are those that have the best conditions for the expression of this character.

Taking into account the favorable and unfavorable environments (Table 6 ) for root dry mass (RDM), the cultivar that was superior was lapar-19 Pioneira and the lowest was BRS CS01, the same pattern was repeated for unfavorable environments. Different from the results found for the percentage of starch (CHO) in the root, where for the most favorable cultivar environments, BRS CS01 stood out, and the one that had the lowest performance was FEPAGRO-RS 13 Vassourinha. However, for the unfavorable environments, the one with the best performance was FEPAGRO-RS 13 Vassourinha and with lower values was lapar-19 Pioneira. 

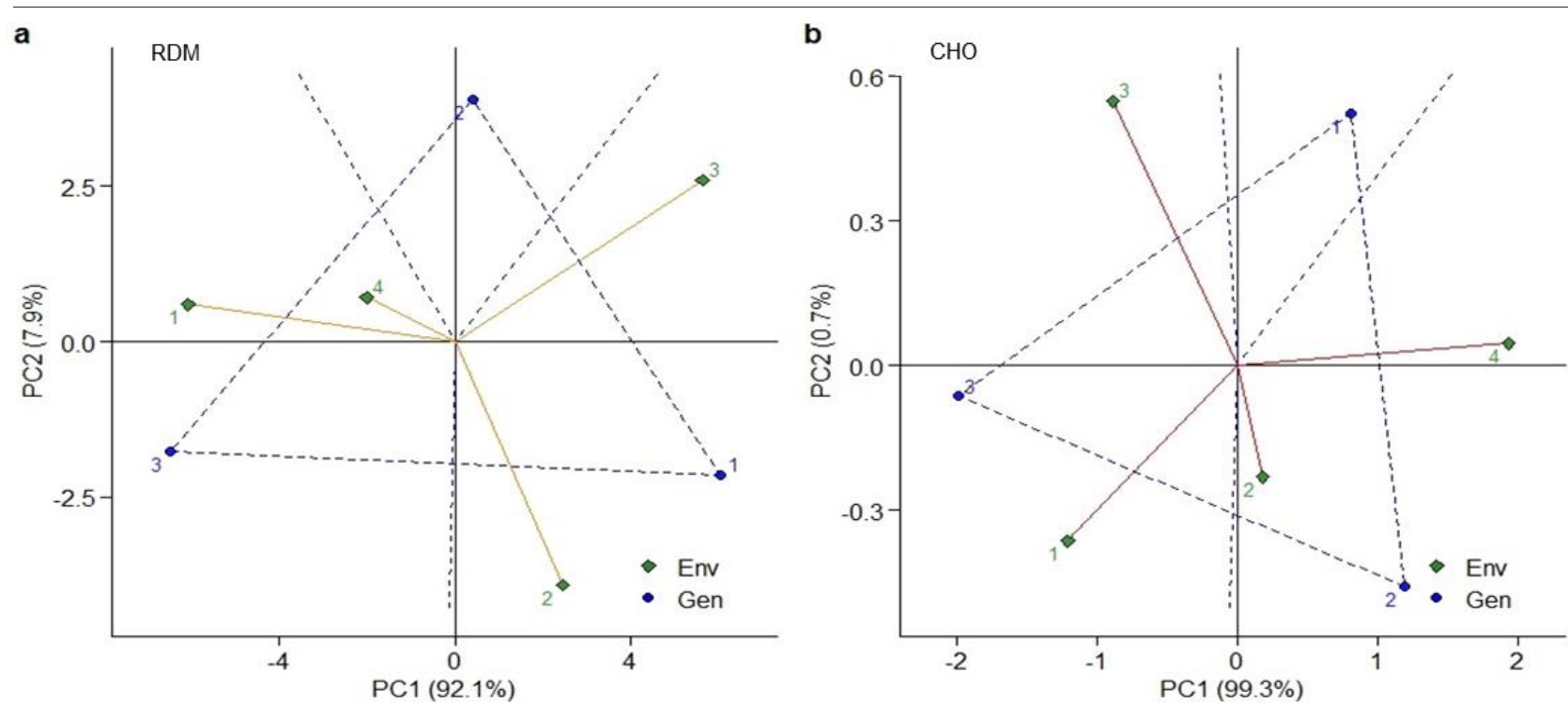

Figure 7. Plot of the scores of the main components, regarding the genotype $x$ environment interaction ( $\mathrm{G} x$ $\mathrm{E})$, according to the AMMI analysis for the production character of Root dry mass (RDM) and Starch (CHO) in four environments (density 10 with biostimulant (1), density 10 without biostimulant (2), density 20 with biostimulant (3), density 20 without biostimulant (4),) and three cultivars (FEPAGRO-RS 13 Vassourinha (1), BRS CS01 (2), lapar-19 Pioneira (3)). Environment (Env), Varieties (Gen).

Table 5. Estimates of confidence indexes by the Annicchiarico method with decomposition in favorable, unfavorable and environmental index, for the character dry root mass (RDM) and percentage of starch $(\mathrm{CHO})$ for the three cassava cultivars in four growing environments.

\begin{tabular}{lccc}
\hline \multicolumn{1}{c}{ Rrowing environments } & RDM mean & Environmental index & Classification $^{\mathbf{1}}$ \\
\hline Density 10 with biostimulant & 335,15 & 50,59 & $\mathrm{~F}$ \\
Density 10 without biostimulant & 272,15 & $-12,41$ & $\mathrm{U}$ \\
Density 20 with biostimulant & 287,31 & 2,75 & $\mathrm{~F}$ \\
Density 10 with biostimulant & 243,63 & $-40,93$ & $\mathrm{U}$ \\
\hline & CHO & & $\mathrm{F}$ \\
\hline Density 10 with biostimulant & 8,27 & 0,03 & $\mathrm{U}$ \\
Density 10 without biostimulant & 7,13 & $-1,11$ & $\mathrm{~F}$ \\
Density 20 with biostimulant & 9,66 & 1,42 & $\mathrm{U}$ \\
Density 20 without biostimulant & 7,91 & $-0,34$ &
\end{tabular}

${ }^{1}$ Favorable (F), Unfavorable (U).

Table 6. Ranking of cultivars within favorable and unfavorable environments for root dry mass ( $\mathrm{rdm})$ and percentage of starch $(\mathrm{CHO})$.

\begin{tabular}{cccc}
\hline & & RDM & \\
\hline Ranking & Favorable & Unfavorable \\
\hline $1^{\text {st }}$ & lapar-19 pioneira & lapar-19 pioneira \\
$2^{\text {nd }}$ & FEPAGRO-RS 13 Vassourinha & FEPAGRO-RS 13 vassourinha \\
$3^{\text {rd }}$ & BRS CS01 & BRS CS01 \\
\hline \multicolumn{3}{c}{ CHO } \\
\hline $1^{\text {st }}$ & BRS CS01 & FEPAGRO-RS 13 Vassourinha \\
$3^{\text {rd }}$ & lapar-19 pioneira & BRS CS01 \\
& FEPAGRO-RS 13 Vassourinha & lapar-19 pioneira \\
\hline
\end{tabular}


The joint interpretation of the linear associations, dendrogram, PCA-biplot and Annicchiarico method allowed to reveal the interrelationships between the characters and to define which of these are determinants to the percentage of starch ( $\mathrm{CHO}$ ) and root dry mass (RDM) of cassava, which environments are favorable or unfavorable and which genotypes are stable and predictable for this trait.

\section{CONCLUSIONS}

Regarding the density, the one that showed a better performance in the productive character was the density 10 buds per linear meter, which presented the highest averages of the commercial fresh mass without peel.

Taking into account the cultivars, the one with the highest fresh mass production was BRS CSO1 and lapar19 Pioneira. However, FEPAGRO-RS 13 Vassourinha presented a higher percentage of starch.

The application of the biostimulant of root growth showed significant effect mainly for the characteristics of productivity.

The increase in the number of branches decreases the final productivity of the crop. Another point to consider, the larger the average root diameter, the greater the percentage of starch in the root.

By the method of Annicchiarico it can be pointed out that in general the percentage of starch and the dry matter of the roots had a better behavior in density 10 with biostimulant and density 20 with biostimulant.

\section{REFERENCES}

Abreu, M. L., Bicudo, S. J., Brachtvogel, E. L., Curcelli, F., \& Aguiar, E. B. (2008). ISSN 1808-981X. Revista Raízes Amidos Tropicais, 4, 43-53. Retrieved from http://revistas.fca.unesp.br/index.php/rat/article/view/1152

Albuquerque, J. A. A. I., Sediyama, T., Silva, A. A., Alves, J. M. A., Finoto, E. L., Neto, F. A., \& Silva, G. R. V. (2012). Desenvolvimento da cultura de mandioca sob interferência de plantas daninhas. Planta Daninha, 30(1), 37-45. https://doi.org/https://doi.org/10.1590/S0100-83582012000100005

Annicchiarico, 2002. (1992). Cultivar adaptation and recommendation from alfalfa trials in northern Italy. J. Genet. Breed., 46: 269-278. J. Genet. \& Breed, 46(January 1992), 269-296. Retrieved from https://www.researchgate.net/profile/Paolo_Annicchiarico/publication/292006732_Cultivar_adaptatio n_and_recommendation_from_alfalfa_trials_in_Northern_Italy/links/58382a1608aed5c614880f4c/Cult ivar-adaptation-and-recommendation-from-alfalfa-trials-in-Northe

Carvalho, F. I. F., Lorencetti, C., \& Benin, G. (2004). Estimativas e implicações da correlação no melhoramento vegetal. Pelotas, RS: Universidade Federal de Pelotas.

CONAB: Companhia Nacional de Abastecimento. (2019). Mandioca: raiz, farinha e fécula. Conjuntura mensal, janeiro de 2019. Brasília, DF: CONAB. Retrieved from https://www.conab.gov.br/infoagro/analises-do-mercado-agropecuario-e-extrativista/analises-do-mercado/historico-mensal-demandioca

CONAB: Companhia Nacional de Abastecimento. (2020). Mandioca: raiz, farinha e fécula. Conjuntura mensal, janeiro de 2020. Brasília, DF: CONAB. Retrieved from https://www.conab.gov.br/infoagro/analises-do-mercado-agropecuario-e-extrativista/analises-do-mercado/historico-mensal-demandioca

Cruz, C. D., Carneiro, P. C. S., \& Regazzi, A. J. (2014). Modelos Biométricos Aplicados ao Melhoramento Genético. Viçosa: Editora UFV.

Cury, G. (2008). Mandioca. In I. Castro, P. R. C., Kluge, R. A., Sestari (Ed.), Manual de fisiologia Vegetal: fisiologia dos cultivos (pp. 113-128). Piracicaba, SP: Editora Agronômica Ceres.

Maluf, J. R. T., Matzenauer, R., \& Maluf, D. E. (2011). Zoneamento agroclimático da mandioca no estado do Rio Grande do Sul - uma alternativa para a produção de etanol. Porto Alegre, RS: Fepagro. Retrieved from https://www.agricultura.rs.gov.br/upload/arquivos/201608/01102437-mandioca-2011.pdf 
Miranda, L. A., Spinosa, W. A., Destro, T. M., Souza-Junior, H., \& Nascimento, V. (2019). Influence of harvest time and agricultural year in yield components of table cassava cultivars. Agronomy Science and Biotechnology, 5(2), 77-88. https://doi.org/10.33158/asb.2019v5i2p77

Miranda, L. A., Spinosa, W. A., Destro, T. M., Souza-Junior, H., \& Nascimento, V. (2020). Sweet cassava cooking time. Agronomy Science and Biotechnology, 6, 1-16. https://doi.org/10.33158/asb.r109.v6.2020

Sangoi, L., \& Kruse, N. D. (1993). Acúmulo e distribuição de matéria seca em diferentes frações da planta da mandioca no planalto catarinense. Pesquisa Agropecuária Brasileira, 28(10), 1151-1164. Retrieved from https://seer.sct.embrapa.br/index.php/pab/article/view/3982

Shapiro, A. S. S., \& Wilk, M. B. (1965). An Analysis of Variance Test for Normality (Complete Samples ) Published by : Biometrika Trust Stable URL : http://www.jstor.org/stable/2333709. Biometrika, 52(3/4), 591-611.

Silva, J. A. G., Carvalho, I. R., \& Magano, D. A. (2020). A cultura da aveia: da semente ao sabor de uma espécie multifuncional. Curitiba, PR: Editora CRV.

Souza, L. S., Farias, A. R. N., Mattos, P. L. P., \& Fukuda, W. M. G. (2006). Aspectos socioeconômicos e agronômicos da mandioca. In A. A. C. Alves (Ed.), Fisiologia da mandioca (pp. 138-169). Brasília, DF: Embrapa.

Takahashi, M., \& Guerini, V. L. (1998). Espaçamento para a cultura da mandioca. Brazilian Archives of Biology and Technology, 41(4), 489-494. https://doi.org/10.1590/S1516-89131998000400014

Tironi, L. F., Zanon, A. J., Alves, A. F., Freitas, C. P. O., Santos, A. T. L., Cardoso, P. S., Tonel, G. P., Rodrigues, L. B., Tagliapietra, B. L., Silva, M. N., \& Streck, N. A. (2019). Ecofisiologia da Mandioca Visando Altas Produtividades. Santa Maria, RS: Equipe Simanihot.

Received: November 27, 2020.

Accepted: December 12, 2020.

Published: January 19, 2021.

\section{English by: Francine Lautenchleger}

